\title{
Calcium intake and the associations with faecal fat and energy excretion, and lipid profile in a free-living population
}

\author{
Louise Kjølbæk*, Janne K. Lorenzen, Lesli H. Larsen and Arne Astrup \\ Department of Nutrition, Exercise and Sports, Faculty of Science, University of Copenhagen, Rolighedsvej 26, 1958 Frederiksberg C, Denmark
}

(Received 11 July 2017 - Accepted 7 August 2017)

Journal of Nutritional Science (2017), vol. 6, e50, page 1 of 10

doi:10.1017/jns.2017.55

Abstract

The aim of the present study was to investigate the associations between the habitual Ca intake and faecal fat and energy excretion as well as blood lipid profile in free-living normal-weight and overweight individuals. The participants were enrolled for an 8 - $\mathrm{d}$ period where data from a 7 -d diet registration (days 1-7), a 5-d faeces collection (days 3-7), a 2-d urine collection (days 5-7), and anthropometric measurements and a fasting blood sample (day 8) were collected. Analyses showed that dietary Ca intake $(\mathrm{g} / 10 \mathrm{MJ}$ per $\mathrm{d})$ was positively associated with excretion of faecal fat $(P=0 \cdot 004)$ and energy $(P=0 \cdot 031)$ when adjusted for BMI, age, sex and intake of Ca-containing supplements. However, after adjustment for intake of fibre, the effect of Ca intake disappeared. Nevertheless, total cholesterol (CHOL) and LDL-CHOL concentrations were associated negatively with Ca intake $(\beta-0.62$ (95 \% CI -0.96 , $-0.28) \mathrm{mmol} / \mathrm{l}, \mathrm{P}<0.001$, and $\beta-0.49(95 \% \mathrm{CI}-0.78,-0.20) \mathrm{mmol} / \mathrm{l}, \mathrm{P}=0.001$, respectively, per $1000 \mathrm{mg} / 10 \mathrm{MJ}$ per $\mathrm{d}$ increase in Ca intake). In conclusion, incorporation of Ca-rich food products in a habitual diet was associated with reduced total CHOL and LDL-CHOL concentrations, which may lower the risk of CVD in the long term.

Key words: Dietary calcium: Faecal fat excretion: Faecal energy excretion: Lipid profile: Cholesterol

More than 1.9 billion adults are overweight or obese worldwide $^{(1)}$ and obesity is considered a global health issue because it increases the risk of CVD and diabetes ${ }^{(1)}$. Weight-loss (maintenance) diets have been intensively investigated, especially with focus on the energy-providing macronutrients ${ }^{(2-5)}$. However, the micronutrient $\mathrm{Ca}$ has been associated with reduced BMI since $1984^{(6)}$. Subsequently, many studies have found negative associations of dairy product or $\mathrm{Ca}$ intakes with anthropometric measurements $^{(6-23)}$. Additionally, a higher $\mathrm{Ca}$ intake has been associated with reduced insulin concentration ${ }^{(15)}$, blood pressure $(B P)^{(6,14,18)}$ and reduced risk of the metabolic syndrome ${ }^{(18,24,25)}$ as well as an improved blood lipid profile ${ }^{(7,18)}$. Nonetheless, the negative anthropometric association with $\mathrm{Ca}$ has not been consistently shown ${ }^{(26-30)}$, and the effect of a higher $\mathrm{Ca}$ intake on body weight has not been clearly proven by randomised controlled trials (RCT) or meta-analyses ${ }^{(31-35)}$.
One of several theories is that Ca binds fat in the intestine, especially the long-chain fatty acids, which causes the formation of insoluble $\mathrm{Ca}$-fatty acid soaps ${ }^{(36,37)}$. The decreased solubility of fatty acids and monoacylglycerols in the micelles lowers cholesterol (CHOL) solubility and causes the formation of large aggregates that are unlikely to be absorbed ${ }^{(38)}$. Thus, a higher $\mathrm{Ca}$ intake will result in increased faecal fat excretion ${ }^{(39)}$. Additionally, Ca precipitates bile acids ${ }^{(40)}$, which reduces the enterohepatic recycling of bile acids and causes de novo synthesis of bile acids from blood CHOL. Overall, this may lead to an improved blood lipid profile.

In observational studies, intakes of dairy products and $\mathrm{Ca}$ have been associated with dyslipidaemia ${ }^{(24)}$, total $\mathrm{CHOL}^{(7,28)}$, LDL-CHOL $^{(7)}$, HDL-CHOL ${ }^{(18)}$, total CHOL:HDL-CHOL ratio ${ }^{(7)}$ and $\mathrm{TAG}^{(24)}$. However, the findings are not consistent. Some studies have found reduced total CHOL and

Abbreviations: BP, blood pressure; CHOL, cholesterol; Q1, first quartile; Q3, third quartile; RCT, randomised controlled trial.

* Corresponding author: L. Kjølbæk, fax +45 3532 1600, email louisekjoelbaek@nexs.ku.dk 
LDL-CHOL concentrations or increased HDL-CHOL concentration associated with reduced risk of $\mathrm{CVD}^{(41-45)}$, but others observed that the total CHOL:HDL-CHOL or LDL-CHOL: HDL-CHOL ratio ${ }^{(42,46,47)}$ was a better predictor for CVD than the isolated blood lipid concentrations. In intervention studies, increased Ca intake from fortified products ${ }^{(48,49)}$, dietary supplements ${ }^{(17,50-53)}$, milk ${ }^{(34,54,55)}$, cheese ${ }^{(55-57)}$, yoghurt $^{(14)}$ and a mixture of dairy products ${ }^{(15,17,35,50,58-60)}$, as well as $\mathrm{Ca}$ intake combined with different fat ${ }^{(61)}$ or protein ${ }^{(60)}$ contents, have been investigated. Still, the exact quantity of faecal fat excretion and effect on the lipid profile in relation to the increased $\mathrm{Ca}$ intake is inconsistent.

A frequently raised concern is whether the short-term effect of $\mathrm{Ca}$ observed in intervention studies will decrease over time due to adaptation to a long-term high habitual Ca intake. Therefore, the aim of the present study was to investigate the association between habitual $\mathrm{Ca}$ intake and faecal fat and energy excretion in free-living normal-weight and overweight persons as well as the association between habitual Ca intake and blood lipid profile.

\section{Participants and methods}

\section{Study design}

The study included participants from two trials with similar design for the baseline measurements. In both trials, data were obtained during an 8 -d period. The participants' dietary intake was assessed by a 7 -d dietary registration where the participants weighed all foods (days 1-7). Participants recorded physical activity, smoking habits, intake of medication and illness on days 1-7 and women recorded their menstrual cycle. Faecal samples were collected in pre-weighed plastic containers over $5 \mathrm{~d}$ (days 3-7) and complete 48-h urine collection was carried out (days 6-7). On day 8, anthropometric measurements and BP measurements were performed and a fasting $(12 \mathrm{~h})$ blood sample was drawn at the Department.

Trial I (clinical trial no. NCT01542164; https://clinicaltrials. gov) was an observational study carried out from June 2009 to March 2011. The primary aim was to investigate the associations between habitual $\mathrm{Ca}$ intake and faecal fat and energy excretion as well as the association between habitual $\mathrm{Ca}$ intake and lipid profile. Individuals were recruited with the goal to obtain forty participants in each of the four groups: (A) $\mathrm{BMI}>25 \mathrm{~kg} / \mathrm{m}^{2}$ and habitual dietary Ca intake $\leq 800 \mathrm{mg} / \mathrm{d}$; (B) $\mathrm{BMI}>25 \mathrm{~kg} / \mathrm{m}^{2}$ and habitual dietary $\mathrm{Ca}$ intake $>800$ $\mathrm{mg} / \mathrm{d}$; (C) $\mathrm{BMI} \leq 25 \mathrm{~kg} / \mathrm{m}^{2}$ and habitual dietary $\mathrm{Ca}$ intake $\leq 800 \mathrm{mg} / \mathrm{d}$; (D) $\mathrm{BMI} \leq 25 \mathrm{~kg} / \mathrm{m}^{2}$ and habitual dietary $\mathrm{Ca}$ intake $\leq 800 \mathrm{mg} / \mathrm{d}$. At inclusion, BMI was calculated from self-reported weight and height and habitual $\mathrm{Ca}$ intake was assessed by a self-administered quantitative FFQ highly similar to a FFQ previously validated ${ }^{(62)}$. Trial II (clinical trial no. NCT01199835; https://clinicaltrials.gov) was an intervention study with a randomised parallel design. Overweight and obese participants (BMI $28-33 \mathrm{~kg} / \mathrm{m}^{2}$ ) were randomised to a 24-week intake of a hypoenergetic diet with either a high or a low intake of dairy products. A minimum of forty (and up to fifty) participants were recruited for each group. It was carried out from June 2010 to August 2011 and the aim was to investigate the effect of the hypoenergetic high- $v$. low-dairy diets on weight loss and faecal excretion of fat and energy. Furthermore, the effects on BP, blood lipid profile, lipid oxidation and appetite regulation were investigated (described elsewhere; Bendtsen et al. $\left.{ }^{(63)}\right)$.

Both studies were conducted according to the guidelines laid down in the Declaration of Helsinki and all procedures involving human participants were approved by the responsible regional committee on human experimentation in Denmark (H-B-2009-071 (trial I) and H-3-2010-049 (trial II)). Furthermore, the studies were registered in Clinical Trial and the Danish Data Protection Agency (both studies: 2007-54-0269). Written informed consent was obtained from all participants and both studies were carried out at the Department of Nutrition, Exercise and Sports, Faculty of Science, University of Copenhagen, Denmark.

\section{Participants}

Individuals were recruited through advertisements posted on a university web page (forsøgsperson.dk) and in the local/free newspaper. Potential individuals were pre-screened by telephone in accordance with the inclusion and exclusion criteria and those who fulfilled the criteria were sent written information and the FFQ. Finally, those who fulfilled BMI and habitual $\mathrm{Ca}$ criteria were invited to an information meeting where the informed consent was signed.

The inclusion criteria in trial I were 18-50 years and weight stable ( $\pm 4 \mathrm{~kg} 4$ months prior to study start), and in trial II participants were 18-60 years and had a habitual low Ca intake $(<800 \mathrm{mg} / \mathrm{d})$ evaluated by the FFQ. In both studies, individuals were excluded if they were pregnant or lactating, used CHOL-decreasing medication or other types of medication assessed to influence the study outcomes. Furthermore, dieting individuals or individuals with a temporary change in dietary habits as well as individuals with previous and present gastrointestinal diseases were excluded. In trial II individuals with milk allergy, infectious disease and metabolic diseases were excluded too. Smokers and individuals who had taken dietary supplements 6 months prior to (and during the study) were excluded in trial II, whereas in trial I participants recorded their smoking habits and intake of dietary supplements. In trial $\mathrm{I}$, individuals with physical activity more than $8 \mathrm{~h} /$ week were excluded. In general, the participants were not allowed to participate in other studies in parallel. However, data collected in trial I constituted the majority of the baseline measurements in trial II; therefore participants were allowed to participate in these two studies at the same time.

As compensation, participants received 1000 Danish Crowns (about US\$185) after completion of trial I. The same compensation was provided in trial II, but only if the participant completed a sub-study.

\section{Outcomes}

The primary outcomes were faecal fat and energy excretion. Secondary outcomes were fasting blood lipid profile (total 
CHOL, LDL-CHOL, HDL-CHOL, NEFA and TAG), resting $\mathrm{BP}$ as well as the faecal and urinary excretion of $\mathrm{Ca}$.

\section{Data collection}

In both trials, data were obtained during an 8-d period. In trial I, data were obtained once. In trial II (the RCT), only baseline data were used for analyses.

Anthropometry and blood pressure. All participants voided before anthropometric measurements were performed. Body weight (in $\mathrm{kg}$ with two decimals) was measured by a digital scale (Lindells). Height was measured twice with $0.5 \mathrm{~cm}$ accuracy using a wall-mounted stadiometer (Hultafors) and the average of the two measurements was recorded. BMI was calculated as weight $(\mathrm{kg})$ divided by height squared $\left(\mathrm{m}^{2}\right)$. After 10 min rest, BP was measured by an automatically inflated cuff (Saitama). BP was measured on both arms and the subsequent measurements were performed on the arm with the highest systolic BP. If the subsequent two measurements differed by more than $5 \mathrm{mmHg}$, additional measurements were performed until two consecutive measurements differed by $\leq 5 \mathrm{mmHg}$ and an average was recorded.

Dietary records. Weighed 7-d diet records were used to evaluate habitual $\mathrm{Ca}$ intake with the assumption that it would reflect a long-term $\mathrm{Ca}$ intake. The participants' dietary intakes of energy, macronutrients and micronutrients were calculated as a daily average from the 7-d diet records. Participants registered all foods and supplied information on brand names, cooking and processing. Whenever possible, foods were weighed; otherwise, household measures were applied. The dietary registrations were assessed by the computer database of foods from the National Food Agency of Denmark (Dankost 3000; National Food Agency of Denmark).

Faeces. Before analysis, faeces samples were weighed, homogenised and freeze-dried, and all samples from the 5-d collection period were pooled. Faecal energy was measured in duplicate by a bomb calorimeter (IKA Calorimeter System C4000) and the average was recorded. Faecal samples were hydrolysed with $3 \mathrm{~m}-\mathrm{HCl}$ and thereafter fat excretion was measured by the acidic Bligh \& Dyer extraction ${ }^{(64)}$. Before analysis of faecal $\mathrm{Ca}$ content, samples were dried at $525^{\circ} \mathrm{C}$ for $6 \mathrm{~h}$, ashes were dissolved in $6.5 \% \mathrm{HNO}_{3}$ and the solution was diluted with a lanthanum chloride solution. To determine Ca content, samples were measured by atomic absorption spectrophotometry using a PYE UNICAM SP9 atomic absorption spectrophotometer (Philips Electron Optics).

Urine. During urine collection, participants ingested tablets of $80 \mathrm{mg}$ para-aminobenzoic acid three times per d (240 $\mathrm{mg} / \mathrm{d})$. Before analysis, weight and density of the collected urine were measured to calculate the volume. Excretion of urinary $\mathrm{Ca}$ was measured using photometric analysis (ABX Pentra 400 analyser; HORIBA ABX S.A.S.) and urinary N using the modified Dumas method with a VarioMax CN analyser (Elementar).

Blood samples. Fasting blood samples for the analysis of serum lipids (total CHOL, LDL-CHOL, HDL-CHOL and TAG) were collected in serum tubes and kept at room temperature for $30 \mathrm{~min}$ to coagulate. Blood samples for plasma analysis of NEFA were collected in EDTA-containing tubes and immediately placed on ice. All samples were centrifuged at $2500 \mathrm{~g}$ for $10 \mathrm{~min}$ at $4^{\circ} \mathrm{C}$ and stored at $-80^{\circ} \mathrm{C}$. Total CHOL and TAG were measured by enzymic photometric tests, and HDL-CHOL, LDL-CHOL and NEFA by enzymic colorimetric tests using a Pentra 400 Analyser (HORIBA ABX). For total CHOL, intra-assay CV was $1.0 \%$, whereas inter-assay $\mathrm{CV}$ was $1.7 \%$. For HDL-CHOL, intra-assay CV was $1.2 \%$, whereas inter-assay $\mathrm{CV}$ was $5.6 \%$. For LDL-CHOL, intra-assay $\mathrm{CV}$ was $2.4 \%$, whereas inter-assay $\mathrm{CV}$ was $3.7 \%$. For NEFA, intra-assay $\mathrm{CV}$ was $1.7 \%$, whereas inter-assay CV was $5.1 \%$. For TAG, intra-assay $\mathrm{CV}$ was $3.0 \%$, whereas inter-assay $\mathrm{CV}$ was $3 \cdot 8 \%$.

\section{Statistical analyses}

Before initiation of trial I, a power calculation was performed using data from other studies. The mean for $\mathrm{Ca}$ intake in Denmark was assumed to be 967 (SD 394) $\mathrm{mg} / \mathrm{d}^{(65)}$ and the standard deviation for the faecal fat excretion was assumed to be $2 \mathrm{~g} / \mathrm{d}^{(53)}$. Based on the standard deviation for fat excretion a study with 160 included participants would have a power of $85 \%$ (accounting for a dropout rate of $10 \%$ ) to detect an association between $\mathrm{Ca}$ intake and faecal fat excretion if the faecal fat excretion increased $1 \mathrm{~g} / \mathrm{d}$ per $1000 \mathrm{mg} / \mathrm{d}$ increase in Ca intake. Later, a meta-analysis ${ }^{(39)}$ found that an increase of 800-6000 $\mathrm{mg}$ Ca per d increased the faecal fat excretion by a standardised mean difference of 0.99 (95\% CI 0.63 , $1 \cdot 34)$, corresponding to about $2 \mathrm{~g} / \mathrm{d}$.

All statistical analyses were performed using STATA (version 10.1). The level of significance was set at $P<0.05$.

The collected data were examined for means, ranges and outliers. Normally distributed data are presented as means and standard deviations, and non-normally distributed data by medians, and first and third quartiles (Q1 and Q3). Categorical data are presented by the number of participants in the group. Associations between two parameters (measurements of $\mathrm{Ca}$, fat and energy) were examined by linear regression. Adjusted $R^{2}$ was used to assess how well the linear regression model predicted the dependent variable. All models were visually inspected by plot of residuals and occasionally the dependent variable was transformed to obtain normality of residuals. Cook's distance was used to identify observations that deviated from the main population; however, none of the observations had a Cook's distance value $\geq 1$.

To analyse the association between dietary $\mathrm{Ca}$ intake $(\mathrm{g} / \mathrm{d})$ and the dependent variable faecal fat excretion $(\mathrm{g} / \mathrm{d})$ a general multiple linear regression (model I) was built containing the covariates of BMI, age, sex and intake of Ca-containing supplements (yes/no). Afterwards, this model was further adjusted 
for energy and fat intakes; thus Ca intake was given as g/10 MJ per $\mathrm{d}$ and faecal fat excretion as a percentage of the fat intake (model II). Further, adjustments for fibre intake and the interaction fibre $\times \mathrm{Ca}$ (model III) were tested because increased fibre intake ${ }^{(66)}$ and possibly also an interaction between fibre and $\mathrm{Ca}^{(67)}$ have been linked to increased faecal fat excretion.

To analyse the association between dietary $\mathrm{Ca}$ intake and the dependent variable faecal energy excretion (or blood lipid concentration ( $\mathrm{mmol} / \mathrm{l}$ or $\mu \mathrm{mol} / \mathrm{l})$ or BP $(\mathrm{mmHg})$ ) a general multiple linear regression (model I) with covariates as described above was built. This model was further adjusted for energy intake; thus $\mathrm{Ca}$ intake was given as $\mathrm{g} / 10 \mathrm{MJ}$ per $\mathrm{d}$ (for investigation of faecal energy excretion this variable was given as a percentage of total energy intake). Further adjustments for fibre and the interaction fibre $\times \mathrm{Ca}$ (model III) were performed as described above.

The possibility that faecal excretion of fat or energy could mediate Ca's association with blood lipid profile was tested by a mediation analysis described by MacKinnon et al. ${ }^{(68)}$.

\section{Results}

In total, 189 participants (129 women and sixty men; Table 1) were included in the final data analysis (Fig. 1). Description of faecal and urine samples is found in Table 2.

The median faecal and urinary $\mathrm{Ca}$ excretion (Table 2) corresponded to a 98 (SD 31) \% excretion of the estimated dietary $\mathrm{Ca}$ intake. There was a positive association between dietary

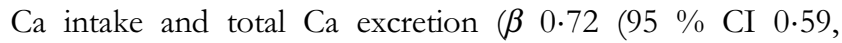
0.86), $\left.P<0.001, R^{2} 0.39\right)$, and positive associations between faecal excretion of $\mathrm{Ca}$ and fat $(\beta 0.32$ (95\% CI $0.26,0 \cdot 38)$, $\left.P<0.001, R^{2} 0.37\right)$ and between faecal excretion of $\mathrm{Ca}$ and energy $\left(\beta 10 \cdot 8\right.$ (95 \% CI 9.19, 12.5), $\left.P<0 \cdot 001, R^{2} 0 \cdot 48\right)$ (Supplementary Fig. S1).

Dietary Ca intake $(\mathrm{g} / \mathrm{d})$ was associated with faecal fat excretion $(\beta 0.20$ (95\% CI 0.12, 0.29); $P<0 \cdot 001)$. For each 1000 $\mathrm{mg} / \mathrm{d}$ increase in Ca intake, faecal fat excretion was predicted to increase by $59(95 \%$ CI 31, 94) \%, which means that faecal fat excretion may increase from, for example, $5.7 \mathrm{~g} / \mathrm{d}$ (Q1) to $9.0 \mathrm{~g} / \mathrm{d}$. After adjustment for fat and energy intakes a 1000 $\mathrm{mg} / 10 \mathrm{MJ}$ per $\mathrm{d}$ increase in $\mathrm{Ca}$ intake was predicted to yield a $31 \%$ higher fat percentage excretion $(P=0.004)$ (Table 3 ). For example, a $6.6 \%$ excretion of the total dietary fat intake (Q1) would increase to $8 \cdot 7 \%$.

Dietary $\mathrm{Ca}$ intake $(\mathrm{g} / \mathrm{d})$ was associated with energy excretion ( $\beta$ 5.74 (95 \% CI 3.26, 8.22); $P<0.001)$. For a woman with a dietary $\mathrm{Ca}$ intake of $856 \mathrm{mg} / \mathrm{d}$ (Q1) (median age and BMI, without consumption of $\mathrm{Ca}$ supplements), a $1000 \mathrm{mg} / \mathrm{d}$ increase in $\mathrm{Ca}$ intake was related to an increase in faecal energy excretion of $344(95 \%$ CI 174, 548) kJ/d. After adjustment for energy intake, the predicted effect on faecal energy excretion was reduced $(P=0.031)$ (Table 4). As exemplified above, a $1000 \mathrm{mg} / 10 \mathrm{MJ}$ per $\mathrm{d}$ increase in $\mathrm{Ca}$ intake would yield a predicted increase in the energy excretion from 8.3 to $9.7 \%$, which corresponds to a $133 \mathrm{~kJ} / \mathrm{d}$ increase for a woman consuming an average energy intake of $9264 \mathrm{~kJ} / \mathrm{d}$.

Further adjustments for fibre intake showed no fibre $\times \mathrm{Ca}$ interaction, either on faecal fat or energy excretion, but adjusting
Table 1. Description of the study population (n 189)

(Medians with quartile 1 (Q1) and quartile 3 (Q3); mean values and standard deviations, unless otherwise specified)

\begin{tabular}{|c|c|c|}
\hline Characteristics & Median & Q1, Q3 \\
\hline Age (years) & 31 & 24,44 \\
\hline \multicolumn{3}{|l|}{ Anthropometry } \\
\hline \multicolumn{3}{|l|}{ Height $(\mathrm{m})^{\star}$} \\
\hline Mean & $1 \cdot 72$ & \\
\hline SD & 0.1 & \\
\hline Weight $(\mathrm{kg})^{*}$ & $76 \cdot 4$ & $68.5,88.9$ \\
\hline BMI $\left(\mathrm{kg} / \mathrm{m}^{2}\right)^{*}$ & $26 \cdot 3$ & $22 \cdot 3,31 \cdot 0$ \\
\hline \multicolumn{3}{|l|}{ Blood pressure } \\
\hline Systolic blood pressure $(\mathrm{mmHg})^{\star}$ & 118 & 111,125 \\
\hline \multicolumn{3}{|l|}{ Diastolic blood pressure $(\mathrm{mmHg})^{*}$} \\
\hline Mean & $76 \cdot 5$ & \\
\hline SD & $10 \cdot 2$ & \\
\hline Pulse (beats/min) ${ }^{\dagger}$ & 60 & 55,65 \\
\hline \multicolumn{3}{|l|}{ Lipid profile } \\
\hline \multicolumn{3}{|l|}{ Total cholesterol $(\mathrm{mmol} / \mathrm{l})^{\ddagger}$} \\
\hline Mean & $4 \cdot 80$ & \\
\hline SD & 1.04 & \\
\hline HDL cholesterol $(\mathrm{mmol} / \mathrm{l})^{\ddagger}$ & 1.38 & $1.14,1.60$ \\
\hline LDL cholesterol $(\mathrm{mmol} / \mathrm{l})^{\star}$ & 2.66 & $2 \cdot 13,3 \cdot 29$ \\
\hline $\mathrm{TAG}(\mathrm{mmol} / \mathrm{l})^{\ddagger}$ & 0.92 & $0.65,1.33$ \\
\hline $\mathrm{NEFA}(\mu \mathrm{mol} / \mathrm{l})^{\star}$ & 587 & 439,735 \\
\hline \multicolumn{3}{|l|}{ Diet } \\
\hline Energy intake (kJ/d) & 9744 & 8392,11451 \\
\hline Protein (E\%) & $15 \cdot 5$ & $13.9,17.5$ \\
\hline \multicolumn{3}{|l|}{ Carbohydrate (E\%) } \\
\hline Mean & $48 \cdot 5$ & \\
\hline $\mathrm{SD}$ & $5 \cdot 22$ & \\
\hline \multicolumn{3}{|l|}{ Fat (E\%) } \\
\hline Mean & $32 \cdot 0$ & \\
\hline $\mathrm{SD}$ & 5.49 & \\
\hline $\operatorname{SFA}(g / d)$ & $29 \cdot 3$ & $22 \cdot 2,36 \cdot 5$ \\
\hline MUFA (g/d) & $26 \cdot 2$ & $21 \cdot 1,32 \cdot 8$ \\
\hline PUFA $(g / d)$ & $13 \cdot 0$ & $10 \cdot 6,16 \cdot 3$ \\
\hline Dietary cholesterol $(\mathrm{mg} / \mathrm{d})^{\ddagger}$ & 308 & 240,375 \\
\hline Dietary fibre $(g / d)$ & $25 \cdot 4$ & $20 \cdot 2,32 \cdot 5$ \\
\hline Dietary Ca intake $(\mathrm{mg} / \mathrm{d})^{\S}$ & 1065 & 856,1330 \\
\hline FFQ: $\mathrm{Ca} \leq 800 \mathrm{mg} / \mathrm{d}(\%)^{\|\| \|}$ & $50 \cdot 8$ & \\
\hline
\end{tabular}

E\%, energy percentage.

* $n 187$.

$\dagger n 161$

$\ddagger n 188$.

$\S$ Habitual Ca intake assessed by a 7-d diet record (without supplements).

\|Value given as a percentage.

ๆ Habitual $\mathrm{Ca}$ intake assessed by FFQ.

for fibre intake, which was significantly associated with increased faecal fat and faecal energy excretion, abolished the positive association between $\mathrm{Ca}$ intake and excretion of faecal fat and energy (Tables 3 and 4). Intake of Ca-containing supplements was not associated with the outcomes in any of the models.

For the lipid profile, we observed that a $1000 \mathrm{mg} / \mathrm{d}$ increase in Ca intake $(\mathrm{g} / \mathrm{d})$ decreased concentrations of total CHOL by $0.47(95 \%$ CI $0.11,0.82) \mathrm{mmol} / \mathrm{l}(P=0.011)$, LDL-CHOL by $0.47(95 \%$ CI $0.17,0.77) \mathrm{mmol} / 1(P=0.002)$ and TAG by $17(95 \%$ CI $1.6,30) \%(P=0.032)$, and reduced the total CHOL:HDL-CHOL ratio by $10(95 \%$ CI $1.4,18) \%$ $(P=0.025)$ and LDL-CHOL:HDL-CHOL ratio by $16(95$ $\%$ CI $2.9,27) \%(P=0.018)$. After adjustment for energy intake, total CHOL and LDL-CHOL concentrations decreased by increasing $\mathrm{Ca}$ intake (Table 5). Adjustment for fibre intake had no significant influence on lipid profile (Table 5). Concentrations of HDL-CHOL, TAG and 


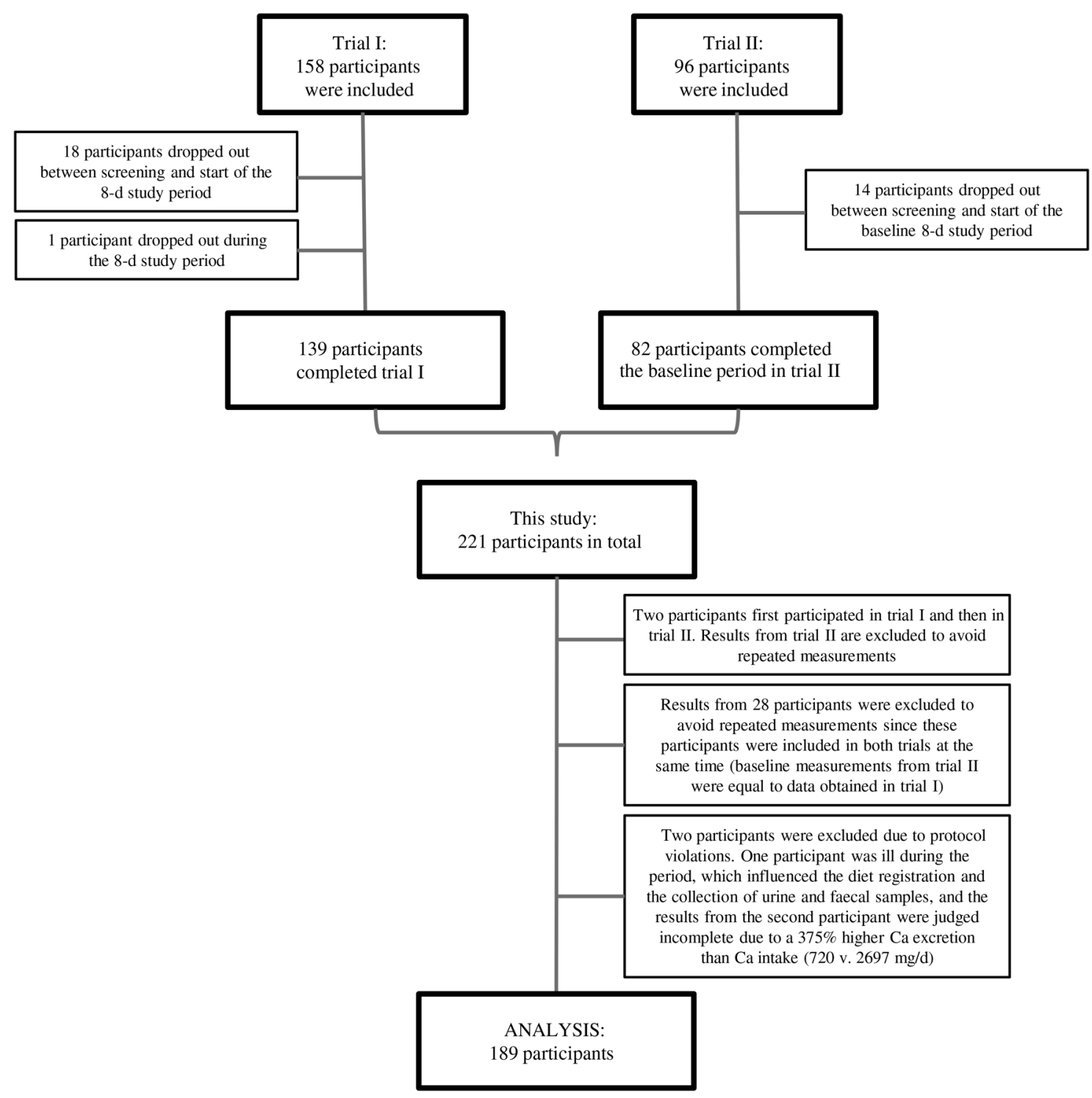

Fig. 1. Flow chart. A total of 158 and ninety-six participants were recruited to trials I and II, respectively. In all, eighteen participants in trial I and fourteen participants in trial II dropped out before the 8-d data collection period started and one participant in trial I dropped out during the data collection period. Hence, 221 participants completed the studies. Before data analysis, thirty participants were excluded to avoid repeated measurement from those who participated in both studies and two participants were excluded due to protocol violation.

NEFA, and the total CHOL:HDL-CHOL and LDL-CHOL: HDL-CHOL ratios were not influenced by $\mathrm{Ca}$ intake when adjusted for energy intake or by further adjustment for fibre intake (Supplementary Table S1). Mediation analysis showed that faecal excretion of fat or energy did not mediate the effect of $\mathrm{Ca}$ intake on lipid profile (Supplementary Table S2).

$\mathrm{Ca}$ intake did not influence systolic BP $(P=0 \cdot 11)$ or diastolic BP $(P=0 \cdot 25)$. However, when the models were energy adjusted, systolic BP decreased $5.2(95 \%$ CI $1.8,8.4) \%$ per $1000 \mathrm{mg} / 10 \mathrm{MJ}$ per $\mathrm{d}$ increase in Ca intake $(P=0.003)$.

\section{Discussion}

We observed that a higher Ca intake was associated with a more beneficial lipid profile, i.e. decreased concentrations of total CHOL and LDL-CHOL as well as a lower systolic BP. Although a higher $\mathrm{Ca}$ intake was associated with higher faecal fat and energy excretion in the models adjusted for energy, BMI, age, sex and intake of Ca-containing supplements, the associations disappeared when adjusted for dietary fibre intake. Thus, the association with blood lipids did not seem to be mediated by higher faecal fat or energy excretion.

A meta-analysis of fifteen RCT found that a daily 800-6000 mg higher Ca intake increased the faecal fat excretion by $2 \mathrm{~g} / \mathrm{d}$, corresponding to a $37 \%$ increase ${ }^{(39)}$. There was no difference in the effect between studies using dairy products $v$. Ca supplements; however, the heterogeneity of the overall analysis $\left(I^{2}=49.5 \%\right)$ suggests possible confounding factors. In our analysis, a daily $1000 \mathrm{mg} / 10 \mathrm{MJ}$ higher $\mathrm{Ca}$ intake was associated with a $31 \%$ increase in fat excretion. However, this association disappeared when the models were adjusted for fibre intake (a possible confounder) and it is questionable how well the effect of fibre intake is considered in the RCT included in the meta-analysis. 
Table 2. Description of faecal and urine samples ( $n$ 189) (Medians with quartile 1 (Q1) and quartile 3 (Q3))

\begin{tabular}{|c|c|c|}
\hline & Median & Q1, Q3 \\
\hline Faecal dry weight (g/d) & $37 \cdot 6$ & $30.5,48.7$ \\
\hline Faecal wet weight $(\mathrm{g} / \mathrm{d})$ & 148 & 113,210 \\
\hline Faecal water content (\%) & $74 \cdot 0$ & $71 \cdot 0,77 \cdot 0$ \\
\hline Faecal energy excretion $(\mathrm{kJ} / \mathrm{d})^{*}$ & 800 & 630,1044 \\
\hline Faecal fat excretion $(\mathrm{g} / \mathrm{d})^{\star}$ & $7 \cdot 68$ & $5.65,10.0$ \\
\hline Faecal Ca excretion $(\mathrm{mg} / \mathrm{d})^{\star}$ & 849 & 637,1126 \\
\hline Urinary Ca excretion $(\mathrm{mg} / \mathrm{d})^{*}$ & 134 & $90 \cdot 0,203$ \\
\hline Total Ca excretion $(\mathrm{mg} / \mathrm{d})^{\dagger}$ & 1044 & 760,1286 \\
\hline
\end{tabular}

${ }^{*} n 186$.

$\dagger n 183$.

Intervention studies have found that higher $\mathrm{Ca}$ intakes from milk or cheese increase faecal fat excretion from 3.9 to 5.2$5.7 \mathrm{~g} / \mathrm{d}$ corresponding to $33-46 \%$ increase per $800 \mathrm{mg} / \mathrm{d}$ $\mathrm{Ca}^{(58)}$, from 5.9 to $8.3 \mathrm{~g} / \mathrm{d}$ corresponding to a $39 \%$ increase per $1500 \mathrm{mg} / \mathrm{d} \mathrm{Ca}^{(61)}$ or tend to increase the faecal fat content from 20 to $23 \%{ }^{(56)}$. The effects in these studies are higher than in our study but one of the main differences between these studies and our study is the amount of $\mathrm{Ca}$. These studies provided very low daily $\mathrm{Ca}$ intake in the control groups $(362$ $\mathrm{mg} / 10 \mathrm{MJ}, 417 \mathrm{mg}, 504 \mathrm{mg} / 10 \mathrm{MJ}$ ), compared with our study where the lowest Ca intake was $498 \mathrm{mg} / \mathrm{d}(557 \mathrm{mg} / 10 \mathrm{MJ}$ per d), and only $10 \%$ of our participants had a Ca intake below $661 \mathrm{mg} / \mathrm{d}(774 \mathrm{mg} / 10 \mathrm{MJ}$ per d). Another observation is the low content of dietary fibres in the intervention diets $(18.4$ $20 \cdot 3 \mathrm{~g} / \mathrm{d}^{(58)}$ or $\left.13 \cdot 5-15 \cdot 3 \mathrm{~g} / 10 \mathrm{MJ}^{(61)}\right)$. In our study the fibre intake was much higher (only $25 \%$ had a fibre intake $<20.2 \mathrm{~g}$ and only $10 \%$ an intake $<17 \cdot 1 \mathrm{~g} / 10 \mathrm{MJ}$ ) and our analysis showed that a $10 \mathrm{~g} / 10 \mathrm{MJ}$ per d increase in fibre intake would increase the faecal fat excretion by $30 \%$. It can be speculated, as indicated by other authors ${ }^{(39,49)}$, that a plateau is reached for the effect of $\mathrm{Ca}$ when the $\mathrm{Ca}$ intake is as high as in our study population. Another interesting observation is the very different amounts of fat excretion in the $\mathrm{RCT}^{(39,58,61)}$. For example, the intake of a milk-based diet (Ca: $1143 \mathrm{mg} / \mathrm{d}$ ) in one study resulted in a fat excretion of
$5.2 \mathrm{~g} / \mathrm{d}^{(58)}$, which was very similar to the fat excretion $(5.87$ $\mathrm{g} / \mathrm{d}$ ) in the control group (Ca: 474-504 mg/10 MJ) of another study $^{(61)}$. A difference like this is probably related to methods for the determination of faecal fat content or other dietary factors that differed between the studies. From our study it is not clear if the increased fat excretion found in RCT is transient or if we do not observe the association in our free-living population because of the habitual intake of $\mathrm{Ca}$ (and fibre) is higher than that provided in intervention diets.

Several studies have shown that increased $\mathrm{Ca}$ intake increases faecal energy excretion ${ }^{(58-61)}$. The increase in energy excretion observed in other studies ranges from 96 to $203 \mathrm{~kJ} / \mathrm{d}$, corresponding to a $13-31 \%$ increase by a $800-1600 \mathrm{mg} / \mathrm{d}$ increase in $\mathrm{Ca}$ intake $\mathrm{e}^{(58,59,61)}$, with one study ${ }^{(60)}$ finding a $361 \mathrm{~kJ} / \mathrm{d}$ increase (about $53 \%$ increase) by a $1300 \mathrm{mg} / \mathrm{d} \mathrm{Ca}$ increase. The former studies are similar to our results showing an increase of $133 \mathrm{~kJ} / \mathrm{d}$ per $1000 \mathrm{mg} \mathrm{Ca} / 10 \mathrm{MJ}$. However, when adjusting for fibre intake the significant association of Ca disappeared in our study.

Similar to our results, Jacqmain et al. ${ }^{(7)}$ investigated data from 470 persons in the Québec Family Study and found that a higher $\mathrm{Ca}$ intake was correlated with a reduced ratio of total CHOL:HDL-CHOL. The ratio of total CHOL: HDL-CHOL for women was significantly reduced by $11.3 \%$ (from 4.16 to 3.69 ) when the $<600 \mathrm{mg} / \mathrm{d}$ Ca group was compared with the $>1000 \mathrm{mg} / \mathrm{d}$ Ca group. In our study, a 1000 $\mathrm{mg} / \mathrm{d}$ increase in $\mathrm{Ca}$ was associated with a $10 \%$ lowered total CHOL:HDL-CHOL ratio; however, this relationship was not significant when adjusted for energy intake. Furthermore, a higher $\mathrm{Ca}$ intake was correlated with reduced concentrations of LDL-CHOL and total $\mathrm{CHOL}^{(7)}$ as we also observed. In agreement with the observational results, Reid $^{(69)}$ reviewed the effect of a higher Ca intake on lipid profile from intervention studies and concluded that higher $\mathrm{Ca}$ intake reduced total CHOL and LDL-CHOL concentrations. Furthermore, a few studies indicated an increase in HDL-CHOL concentration ${ }^{(69)}$ which we did not find. Several interventions ${ }^{(55-57)}$ have found that a cheese diet $(+800 \mathrm{mg} / \mathrm{d} \mathrm{Ca})$ reduced concentrations of total CHOL by

Table 3. Determinants of faecal fat excretion* ( $\beta$ Values and $95 \%$ confidence intervals)

\begin{tabular}{|c|c|c|c|c|c|c|}
\hline \multirow[b]{2}{*}{$\log ($ fat \% (\%)) } & \multicolumn{3}{|c|}{ Model II ${ }^{\dagger}(n$ 182) } & \multicolumn{3}{|c|}{ Model III $(n$ 182) } \\
\hline & $\beta$ & $95 \% \mathrm{Cl}$ & $P$ & $\beta$ & $95 \% \mathrm{Cl}$ & $P$ \\
\hline Ca intake ( $\Delta 1 \mathrm{~g} / 10 \mathrm{MJ}$ per $\mathrm{d})$ & 0.12 & $0.04,0.20$ & 0.004 & 0.05 & $-0.02,0.12$ & 0.19 \\
\hline Age $(\Delta 10$ years $)$ & 0.01 & $-0.02,0.04$ & 0.67 & -0.01 & $-0.03,0.02$ & 0.67 \\
\hline \multicolumn{7}{|l|}{ Sex } \\
\hline Women & Ref. & & & Ref. & & \\
\hline Men & -0.02 & $-0.08,0.05$ & 0.64 & 0.01 & $-0.04,0.07$ & 0.63 \\
\hline $\mathrm{BMI}\left(\Delta 5 \mathrm{~kg} / \mathrm{m}^{2}\right)$ & -0.03 & $-0.06,0.01$ & 0.10 & -0.01 & $-0.04,0.03$ & 0.74 \\
\hline \multicolumn{7}{|l|}{ Ca supplements } \\
\hline No & Ref. & & & Ref. & & \\
\hline Yes & 0.01 & $-0.07,0.08$ & 0.85 & 0.01 & $-0.06,0.07$ & 0.85 \\
\hline Dietary fibre ( $\Delta 5 \mathrm{~g} / 10 \mathrm{MJ}$ per $\mathrm{d})$ & - & - & - & 0.06 & $0.04,0.07$ & $<0.001$ \\
\hline
\end{tabular}

Fat \%, percentage fat excreted; Ref., reference value.

${ }^{*}$ All $\beta$ values and $95 \%$ confidence intervals in the table are raw data, i.e. data have not been back-transformed.

† Percentage fat excreted (fat \%) (calculated as faecal fat excreted/fat intake $\times 100$ ) was log-transformed and analysed by linear regression model adjusted for age, sex, BMI and supplements containing $\mathrm{Ca}$ to investigate the effect of $\mathrm{Ca}$ intake $(\mathrm{g} / 10 \mathrm{MJ}$ per $\mathrm{d})$.

$\ddagger$ Model II + additional adjustment for fibre intake. The interaction fibre $\times \mathrm{Ca}$ was not significant $(P=0.95)$ and therefore removed from the model. 
Table 4. Determinants of faecal energy excretion* ( $\beta$ Values and $95 \%$ confidence intervals)

\begin{tabular}{|c|c|c|c|c|c|c|}
\hline \multirow[b]{2}{*}{ Square root (energy \% (\%)) } & \multicolumn{3}{|c|}{ Model $\mathrm{II}^{\dagger}(n$ 182) } & \multicolumn{3}{|c|}{ Model III ${ }^{\ddagger}(n$ 181) } \\
\hline & $\beta$ & $95 \% \mathrm{Cl}$ & $P$ & $\beta$ & $95 \% \mathrm{Cl}$ & $P$ \\
\hline Ca intake $(\Delta 1 \mathrm{~g} / 10 \mathrm{MJ}$ per $\mathrm{d})$ & 0.24 & $0.02,0.46$ & 0.031 & 0.07 & $-0.14,0.28$ & 0.50 \\
\hline Age ( $\Delta 10$ years $)$ & 0.05 & $-0.04,0.13$ & 0.26 & 0.02 & $-0.06,0.10$ & 0.68 \\
\hline \multicolumn{7}{|l|}{ Sex } \\
\hline Women & Ref. & & & Ref. & & \\
\hline Men & -0.06 & $-0.23,0.12$ & 0.52 & 0.02 & $-0.14,0.18$ & 0.83 \\
\hline BMI $\left(\Delta 5 \mathrm{~kg} / \mathrm{m}^{2}\right)$ & -0.09 & $-0.18,0.01$ & 0.08 & -0.03 & $-0.12,0.06$ & 0.57 \\
\hline \multicolumn{7}{|l|}{ Ca supplements } \\
\hline No & Ref. & & & Ref. & & \\
\hline Yes & 0.02 & $-0.18,0.22$ & 0.84 & 0.02 & $-0.17,0.20$ & 0.84 \\
\hline Dietary fibre $(\Delta 5 \mathrm{~g} / 10 \mathrm{MJ}$ per $\mathrm{d})$ & - & - & - & 0.14 & $0.10,0.19$ & $<0.001$ \\
\hline
\end{tabular}

Energy \%, percentage energy excreted; Ref., reference value.

${ }^{*}$ All $\beta$ values and $95 \%$ confidence intervals in the table are raw data, i.e. data have not been back-transformed.

† Percentage energy excreted (energy \%) (calculated as faecal energy excreted/total energy intake $\times 100$ ) was square root-transformed and analysed by linear regression model adjusted for age, sex, BMI and supplements containing Ca to investigate the effect of Ca intake ( $\mathrm{g} / 10 \mathrm{MJ}$ per d).

$\ddagger$ Model II + additional adjustment for fibre intake. The interaction fibre $\times$ Ca was not significant $(P=0.99)$ and therefore removed from the model.

$0 \cdot 21-0.26 \mathrm{mmol} / 1$ and LDL-CHOL by $0.20-0.22 \mathrm{mmol} / \mathrm{l}$, compared with a butter diet. In the present study, we found an association of a $0.62 \mathrm{mmol} / \mathrm{l}$ reduction in total CHOL concentration per $1000 \mathrm{mg} / 10 \mathrm{MJ}$ per $\mathrm{d}$ increase in Ca intake, which is a larger predicted effect than that observed in other studies ${ }^{(55-57)}$. Furthermore, LDL-CHOL concentration was associated with a $0.49 \mathrm{mmol} / 1$ reduction per $1000 \mathrm{mg} / 10$ $\mathrm{MJ}$ per $\mathrm{d}$ increase in $\mathrm{Ca}$ intake and again a larger predicted effect than observed in the intervention studies ${ }^{(55-57)}$. In our study, increased Ca intake did not increase HDL-CHOL concentration, and the reduced TAG concentration as well as the reduced ratios of total CHOL:HDL-CHOL and LDL-CHOL: HDL-CHOL disappeared when we adjusted for energy intake. These latter observations add to the inconsistency in these lipid markers where only a few studies ${ }^{(50,56)}$ have found effects of increasing $\mathrm{Ca}$ intake. In contrast, Zemel et al. ${ }^{(15)}$ and Jacobsen et al. ${ }^{(60)}$ did not find either long-term or short-term periods on low $v$. high dairy consumption to affect lipid profile and Boon $e t a l .{ }^{(50)}$ only found an effect on TAG concentration.

Many interventions are not directly comparable with our study since they provided diets with a high fat ${ }^{(54)}$ or high SFA $^{(48,49,58)}$ content; thus the CHOL concentrations were expected to increase during the intervention despite the higher $\mathrm{Ca}$ intake. Increased $\mathrm{Ca}$ intake $(800-1500 \mathrm{mg} / \mathrm{d})$ reduced the total CHOL and LDL-CHOL concentrations measured after the intervention in the high $\mathrm{Ca}$ group, compared with the low Ca groups ${ }^{(54,58)}$. Comparable with our results, concentrations of total CHOL differed by $0.29-0.48 \mathrm{mmol} / 1$ and LDL-CHOL by $0.33-0.46 \mathrm{mmol} / \mathrm{l}^{(54,58)}$. These effects have also been observed by Ca-fortified products where a 1011 $\mathrm{mg} / \mathrm{d}$ increase in Ca intake decreased total CHOL concentration by $0.24 \mathrm{mmol} / 1$ and tended to decrease LDL-CHOL concentration by $0.14 \mathrm{mmol} / \mathrm{l}^{(49)}$. Furthermore, a $900 \mathrm{mg} / \mathrm{d}$ increase in $\mathrm{Ca}$ resulted in a $0.33 \mathrm{mmol} / \mathrm{l}$ reduction in LDL-CHOL concentration ${ }^{(48)}$. The majority of studies investigating lipid profile are in agreement with our results showing that an increased $\mathrm{Ca}$ intake reduces total $\mathrm{CHOL}$ and LDL-CHOL concentrations. However, some studies comparing more than one intervention diet did not always find a clear dose-response pattern in the $\mathrm{Ca}$ effect within their study ${ }^{(50,55,57,60)}$ and we did not observe a clear dose-response pattern when we grouped participants into tertiles based on their Ca intake (data not shown). This could indicate that there are unexplained effects related to the food matrix.

Table 5. Determinants of lipid profile

( $\beta$ Values and $95 \%$ confidence intervals)

\begin{tabular}{|c|c|c|c|c|c|c|c|}
\hline \multirow[b]{2}{*}{ Total CHOL (mmol/l) $(n 184)$} & \multicolumn{3}{|c|}{ Model II* } & \multicolumn{4}{|c|}{ Model II* } \\
\hline & $\beta$ & $95 \% \mathrm{Cl}$ & $P$ & LDL-CHOL (mmol/l) (n 183) & $\beta$ & $95 \% \mathrm{Cl}$ & $P$ \\
\hline Ca intake ( $\Delta 1 \mathrm{~g} / 10 \mathrm{MJ}$ per $\mathrm{d})$ & -0.62 & $-0.96,-0.28$ & $<0.001$ & Ca intake $(\Delta 1 \mathrm{~g} / 10 \mathrm{MJ}$ per $\mathrm{d})$ & -0.49 & $-0.78,-0.20$ & 0.001 \\
\hline Age ( $\Delta 10$ years $)$ & 0.36 & $0.22,0.49$ & $<0.001$ & Age $(\Delta 10$ years $)$ & 0.33 & $0.22,0.45$ & $<0.001$ \\
\hline Sex & & & & Sex & & & \\
\hline Women & Ref. & & & Women & Ref. & & \\
\hline Men & -0.31 & $-0.58,-0.04$ & 0.027 & Men & 0.05 & $-0.19,0.28$ & 0.70 \\
\hline $\mathrm{BMI}\left(\Delta 5 \mathrm{~kg} / \mathrm{m}^{2}\right)$ & 0.20 & $0.05,0.34$ & 0.011 & $\operatorname{BMI}\left(\Delta 5 \mathrm{~kg} / \mathrm{m}^{2}\right)$ & 0.19 & $0.06,0.31$ & 0.004 \\
\hline Ca supplements & & & & Ca supplements & & & \\
\hline No & Ref. & & & No & Ref. & & \\
\hline Yes & 0.05 & $-0.27,0.37$ & 0.76 & Yes & 0.02 & $-0.25,0.29$ & 0.89 \\
\hline
\end{tabular}

CHOL, cholesterol; Ref., reference value.

* Lipid outcome analysed by linear regression model adjusted for age, sex, BMI, supplements containing Ca and energy intake to investigate the effect of Ca intake (g/10 MJ per d). Additional adjusting for interaction fibre $\times$ Ca was not significant (total CHOL $P=0.48$, LDL-CHOL: $P=0.28$ ) and therefore removed from the model. Neither had fibre intake a significant influence on the models (total CHOL $P=0.14$, LDL-CHOL $P=0.21$ ) and model III for total CHOL and LDL-CHOL were therefore not different from model II. 
We observed an association of a $5.2 \%$ reduction in systolic BP per $1000 \mathrm{mg} / 10 \mathrm{MJ}$ per $\mathrm{d}$ increase in Ca intake with no relation to diastolic BP. This prediction is higher than findings from two meta-analyses ${ }^{(70,71)}$ that both found a smaller $(0 \cdot 9-$ $1.4 \mathrm{mmHg}$ ) effect on systolic BP.

In general, the predicted effects of $\mathrm{Ca}$ intake on blood lipid profile found in our free-living population are in agreement with effects found in intervention studies; however, it is important to consider the effect size. Elevated LDL-CHOL concentration is associated with an increased risk of CVD and a reduction of $1.0 \mathrm{mmol} / 1$ is estimated to reduce all-cause mortality by $10 \%$ and death related to CVD by $20 \%{ }^{(41)}$. This reduction of LDL-CHOL concentration by entirely increasing $\mathrm{Ca}$ intake will in our study require a $2 \mathrm{~g} / \mathrm{d}$ increase in $\mathrm{Ca}$ intake, which does not seem realistic when the habitual $\mathrm{Ca}$ intake for many Danes is relatively high. However, increasing $\mathrm{Ca}$ intake may be considered as a part of a preventive healthy diet for those with a habitual low Ca intake.

The major limitation in this study is that the study population does not necessarily reflect the general Danish population. In Denmark, habitual Ca intake is high and to obtain associations over a large range in $\mathrm{Ca}$ intake, we aimed at recruiting $50 \%$ of the participants with a Ca intake below $800 \mathrm{mg} / \mathrm{d}$. To obtain data from participants with a low $\mathrm{Ca}$ intake, we included baseline data from participants in trial II that were collected in the same time period and by the exact same methods as in trial I. The inclusion of data from fifty extra participants broadens the Ca range, thus reducing the possibility of making a type II error. Furthermore, we did not find an association of Ca-containing supplements, which could be caused by the fact that (1) too few of our participants consumed supplements, (2) the effect of additional $\mathrm{Ca}$ from supplements reached a $\mathrm{Ca}$ threshold or (3) the information obtained about intake of $\mathrm{Ca}$ supplementation was too limited. In total, thirty-three participants consumed $\mathrm{Ca}$ supplements in the present study and excluding these participants from the analyses did not alter the results.

The major strength of this study is that faeces and urine samples were collected for 5 and $2 \mathrm{~d}$, respectively. The median (Q1, Q3) percentage of relative Ca excretion (urine and faecal Ca excretion/Ca intake) was $94(79,115) \%$, indicating good concordance between $\mathrm{Ca}$ measurements from the urine and faecal samples and the diet registration. Additionally, we included data that allowed us to investigate the association of dietary fibre, which may be a potential confounder of the effect of $\mathrm{Ca}$ intake in relation to energy and fat excretion in our population.

In conclusion, dietary $\mathrm{Ca}$ intake is negatively associated with total CHOL and LDL-CHOL concentrations and systolic BP. Under free-living conditions, these associations do not seem to be mediated by increased faecal excretion of fat or energy.

\section{Supplementary material}

The supplementary material for this article can be found at https://doi.org/10.1017/jns.2017.55

\section{Acknowledgements}

The authors wish to thank the study participants, laboratory technician Jane Jørgensen, good clinical practice coordinator Lene Stevner as well as the study staff involved in the trials at the Department of Nutrition, Exercise and Sports, University of Copenhagen. Furthermore, we would like to thank the staff at Foulum, who analysed faecal fat and Ca contents.

The study was supported by the Danish Dairy Research Foundation, the Danish Council for Strategic Research and Arla Foods amba. The supporting agencies had no role in the design, analysis or writing of this article.

L. K., J. K. L., A. A. and L. H. L. have received funding for research from Arla Foods A/S, Denmark, and the Danish Dairy Research Foundation.

The authors' contributions were as follows: A. A. and J. K. L. formulated the research question and designed the study; J. K. L. conducted research; L. K. and L. H. L. analysed data and wrote the paper, L. K. and L. H. L. have the primary responsibility for final content. All authors critically reviewed the manuscript and approved the final manuscript.

\section{References}

1. World Health Organization (2014) Global Status Report on Noncommunicable Diseases 2014. Geneva: World Health Organization.

2. Hooper L, Abdelhamid A, Moore HJ, et al. (2012) Effect of reducing total fat intake on body weight: systematic review and meta-analysis of randomised controlled trials and cohort studies. BMJ 345, e7666.

3. Johansson K, Neovius M \& Hemmingsson E (2014) Effects of anti-obesity drugs, diet, and exercise on weight-loss maintenance after a very-low-calorie diet or low-calorie diet: a systematic review and meta-analysis of randomized controlled trials. Am J Clin Nutr 99, 14-23.

4. Wycherley TP, Moran LJ, Clifton PM, et al. (2012) Effects of energy-restricted high-protein, low-fat compared with standardprotein, low-fat diets: a meta-analysis of randomized controlled trials. Am J Clin Nutr 96, 1281-1298.

5. Schwingshackl L \& Hoffmann G (2013) Long-term effects of low glycemic index/load $v$ s. high glycemic index/load diets on parameters of obesity and obesity-associated risks: a systematic review and meta-analysis. Nutr Metab Cardiovasc Dis 23, 699-706.

6. McCarron DA, Morris CD, Henry HJ, et al. (1984) Blood pressure and nutrient intake in the United States. Science 224, 1392-1398.

7. Jacqmain M, Doucet E, Despres JP, et al. (2003) Calcium intake, body composition, and lipoprotein-lipid concentrations in adults. Am J Clin Nutr 77, 1448-1452.

8. Davies KM, Heaney RP, Recker RR, et al. (2000) Calcium intake and body weight. J Clin Endocrinol Metab 85, 4635-4638.

9. Loos RJ, Rankinen T, Leon AS, et al. (2004) Calcium intake is associated with adiposity in black and white men and white women of the HERITAGE Family Study. J Nutr 134, 1772-1778.

10. Buchowski MS, Semenya J \& Johnson AO (2002) Dietary calcium intake in lactose maldigesting intolerant and tolerant African-American women. J Am Coll Nutr 21, 47-54.

11. Heaney RP, Davies KM \& Barger-Lux MJ (2002) Calcium and weight: clinical studies. J Am Coll Nutr 21, 152S-155S.

12. Lovejoy JC, Champagne CM, Smith SR, et al. (2001) Ethnic differences in dietary intakes, physical activity, and energy expenditure in middle-aged, premenopausal women: the Healthy Transitions Study. Am J Clin Nutr 74, 90-95.

13. Shahar DR, Abel R, Elhayany A, et al. (2007) Does dairy calcium intake enhance weight loss among overweight diabetic patients? Diabetes Care 30, 485-489. 
14. Zemel MB, Richards J, Mathis S, et al. (2005) Dairy augmentation of total and central fat loss in obese subjects. Int J Obes (Lond) 29, 391-397.

15. Zemel MB, Richards J, Milstead A, et al. (2005) Effects of calcium and dairy on body composition and weight loss in African-American adults. Obes Res 13, 1218-1225.

16. Zemel MB, Shi H, Greer B, et al. (2000) Regulation of adiposity by dietary calcium. FASEB J 14, 1132-1138.

17. Zemel MB, Thompson W, Milstead A, et al. (2004) Calcium and dairy acceleration of weight and fat loss during energy restriction in obese adults. Obes Res 12, 582-590.

18. Azadbakht L, Mirmiran P, Esmaillzadeh A, et al. (2005) Dairy consumption is inversely associated with the prevalence of the metabolic syndrome in Tehranian adults. Am J Clin Nutr 82, 523-530.

19. Rosell M, Johansson G, Berglund L, et al. (2004) Associations between the intake of dairy fat and calcium and abdominal obesity. Int J Obes Relat Metab Disord 28, 1427-1434.

20. Lin YC, Lyle RM, McCabe LD, et al. (2000) Dairy calcium is related to changes in body composition during a two-year exercise intervention in young women. $J$ Am Coll Nutr 19, 754-760.

21. Caan B, Neuhouser M, Aragaki A, et al. (2007) Calcium plus vitamin D supplementation and the risk of postmenopausal weight gain. Arch Intern Med 167, 893-902.

22. Larsen SC, Angquist L, Ahluwalia TS, et al. (2014) Interaction between genetic predisposition to obesity and dietary calcium in relation to subsequent change in body weight and waist circumference. Am J Clin Nutr 99, 957-965.

23. Eagan MS, Lyle RM, Gunther CW, et al. (2006) Effect of 1-year dairy product intervention on fat mass in young women: 6-month follow-up. Obesity (Silver Spring) 14, 2242-2248.

24. Pereira MA, Jacobs DR Jr, Van Horn L, et al. (2002) Dairy consumption, obesity, and the insulin resistance syndrome in young adults: the CARDIA Study. JAMA 287, 2081-2089.

25. Elwood PC, Pickering JE \& Fehily AM (2007) Milk and dairy consumption, diabetes and the metabolic syndrome: the Caerphilly Prospective Study. J Epidemiol Community Health 61, 695-698.

26. Boon N, Koppes LL, Saris WH, et al. (2005) The relation between calcium intake and body composition in a Dutch population: the Amsterdam Growth and Health Longitudinal Study. Am J Epidemiol 162, 27-32.

27. Kamycheva E, Joakimsen RM \& Jorde R (2003) Intakes of calcium and vitamin $\mathrm{D}$ predict body mass index in the population of Northern Norway. J Nutr 133, 102-106.

28. Rajpathak SN, Rimm EB, Rosner B, et al. (2006) Calcium and dairy intakes in relation to long-term weight gain in US men. Am J Clin Nutr 83, 559-566.

29. Brooks BM, Rajeshwari R, Nicklas TA, et al. (2006) Association of calcium intake, dairy product consumption with overweight status in young adults (1995-1996): the Bogalusa Heart Study. J Am Coll Nutr 25, 523-532.

30. Murakami K, Okubo H \& Sasaki S (2006) No relation between intakes of calcium and dairy products and body mass index in Japanese women aged 18 to 20 y. Nutrition 22, 490-495.

31. Trowman R, Dumville JC, Hahn S, et al. (2006) A systematic review of the effects of calcium supplementation on body weight. BrJ Nutr 95, 1033-1038.

32. Barr SI (2003) Increased dairy product or calcium intake: is body weight or composition affected in humans? J Nutr 133, 245S-248S.

33. Gunther CW, Legowski PA, Lyle RM, et al. (2005) Dairy products do not lead to alterations in body weight or fat mass in young women in a 1-y intervention. Am J Clin Nutr 81, $751-756$.

34. Thompson WG, Rostad HN, Janzow DJ, et al. (2005) Effect of energy-reduced diets high in dairy products and fiber on weight loss in obese adults. Obes Res 13, 1344-1353.

35. Bowen J, Noakes M \& Clifton PM (2005) Effect of calcium and dairy foods in high protein, energy-restricted diets on weight loss and metabolic parameters in overweight adults. Int J Obes (Lond) 29, 957-965.

36. Govers MJ \& Van der Meet R (1993) Effects of dietary calcium and phosphate on the intestinal interactions between calcium, phosphate, fatty acids, and bile acids. Gut 34, 365-370.

37. Gacs G \& Barltrop D (1977) Significance of Ca-soap formation for calcium absorption in the rat. Gut 18, 64-68.

38. Vinarova L, Vinarov Z, Tcholakova S, et al. (2016) The mechanism of lowering cholesterol absorption by calcium studied by using an in vitro digestion model. Food Funct 7, 151-163.

39. Christensen R, Lorenzen JK, Svith CR, et al. (2009) Effect of calcium from dairy and dietary supplements on faecal fat excretion: a meta-analysis of randomized controlled trials. Obes Rev 10, 475-486.

40. Govers MJ, Termont DS, Van Aken GA, et al. (1994) Characterization of the adsorption of conjugated and unconjugated bile acids to insoluble, amorphous calcium phosphate. J Lipid Res 35, 741-748.

41. Mihaylova B, Emberson J, Blackwell L, et al. (2012) The effects of lowering LDL cholesterol with statin therapy in people at low risk of vascular disease: meta-analysis of individual data from 27 randomised trials. Lancet 380, 581-590.

42. Lewington S, Whitlock G, Clarke R, et al. (2007) Blood cholesterol and vascular mortality by age, sex, and blood pressure: a meta-analysis of individual data from 61 prospective studies with 55,000 vascular deaths. Lancet 370, 1829-1839.

43. Gordon DJ, Probstfield JL, Garrison RJ, et al. (1989) High-density lipoprotein cholesterol and cardiovascular disease. Four prospective American studies. Circulation 79, 8-15.

44. Kitamura A, Iso H, Naito Y, et al. (1994) High-density lipoprotein cholesterol and premature coronary heart disease in urban Japanese men. Circulation 89, 2533-2539.

45. Yaari S, Goldbourt U, Even-Zohar S, et al. (1981) Associations of serum high density lipoprotein and total cholesterol with total, cardiovascular, and cancer mortality in a 7-year prospective study of 10,000 men. Lancet i, 1011-1015.

46. Castelli WP (1996) Lipids, risk factors and ischaemic heart disease. Atherosclerosis 124, Suppl., S1-S9.

47. Millan J, Pinto X, Munoz A, et al. (2009) Lipoprotein ratios: physiological significance and clinical usefulness in cardiovascular prevention. Vasc Health Risk Manag 5, 757-765.

48. Shahkhalili Y, Murset C, Meirim I, et al. (2001) Calcium supplementation of chocolate: effect on cocoa butter digestibility and blood lipids in humans. Am J Clin Nutr 73, 246-252.

49. Ditscheid B, Keller S \& Jahreis G (2005) Cholesterol metabolism is affected by calcium phosphate supplementation in humans. J Nutr 135, 1678-1682.

50. Boon N, Hul GB, Stegen JH, et al. (2007) An intervention study of the effects of calcium intake on faecal fat excretion, energy metabolism and adipose tissue mRNA expression of lipid-metabolism related proteins. Int J Obes (Lond) 31, 1704-1712.

51. Denke MA, Fox MM \& Schulte MC (1993) Short-term dietary calcium fortification increases fecal saturated fat content and reduces serum lipids in men. J Nutr 123, 1047-1053.

52. Govers MJ, Termont DS, Lapre JA, et al. (1996) Calcium in milk products precipitates intestinal fatty acids and secondary bile acids and thus inhibits colonic cytotoxicity in humans. Cancer Res 56, 3270-3275.

53. Welberg JW, Monkelbaan JF, de Vries EG, et al. (1994) Effects of supplemental dietary calcium on quantitative and qualitative fecal fat excretion in man. Ann Nutr Metab 38, 185-191.

54. Lorenzen JK, Jensen SK \& Astrup A (2014) Milk minerals modify the effect of fat intake on serum lipid profile: results from an animal and a human short-term study. Br J Nutr 111, 1412-1420.

55. Tholstrup T, Hoy CE, Andersen LN, et al. (2004) Does fat in milk, butter and cheese affect blood lipids and cholesterol differently? J Am Coll Nutr 23, 169-176.

56. Hjerpsted J, Leedo E \& Tholstrup T (2011) Cheese intake in large amounts lowers LDL-cholesterol concentrations compared 
with butter intake of equal fat content. Am J Clin Nutr 94, 1479-1484.

57. Biong AS, Muller H, Seljeflot I, et al. (2004) A comparison of the effects of cheese and butter on serum lipids, haemostatic variables and homocysteine. Br J Nutr 92, 791-797.

58. Soerensen KV, Thorning TK, Astrup A, et al. (2014) Effect of dairy calcium from cheese and milk on fecal fat excretion, blood lipids, and appetite in young men. Am J Clin Nutr 99, 984-991.

59. Bendsen NT, Hother AL, Jensen SK, et al. (2008) Effect of dairy calcium on fecal fat excretion: a randomized crossover trial. Int $J$ Obes (Lond) 32, 1816-1824.

60. Jacobsen R, Lorenzen JK, Toubro S, et al. (2005) Effect of shortterm high dietary calcium intake on 24-h energy expenditure, fat oxidation, and fecal fat excretion. Int J Obes (Lond) 29, 292-301.

61. Lorenzen JK \& Astrup A (2011) Dairy calcium intake modifies responsiveness of fat metabolism and blood lipids to a high-fat diet. Br J Nutr 105, 1823-1831.

62. Mølgaard C, Sandström B \& Michaelsen KF (1998) Evaluation of a food frequency questionnaire for assessing of calcium, protein and phosphorus intakes in children and adolescents. Scand J Nutr 42, $2-5$.

63. Bendtsen LQ, Blædel T, Holm JB, et al. (2017) High intake of dairy during energy restriction does not affect energy balance or the intestinal microflora compared to low dairy intake in overweight individuals in a randomized controlled trial. Appl Physiol Nutr Metab (In the Press).
64. Jensen SK (2008) Improved Bligh and Dyer extraction procedure. Lipid Technol 20, 280-281.

65. Lyhne N, Christensen T, Groth MV, et al. (2005) Danskernes kostvaner 2000-2002: Hovedresultater (Danish Dietary Habits 2000-2002: Main Results). Søborg, Denmark: Danmarks Fødevareforskning

66. Kristensen M, Jensen MG, Aarestrup J, et al. (2012) Flaxseed dietary fibers lower cholesterol and increase fecal fat excretion, but magnitude of effect depend on food type. Nutr Metab (Lond) 9, 8.

67. Nybroe S, Astrup A \& Bjornvad CR (2016) Dietary supplementation with flaxseed mucilage alone or in combination with calcium in dogs: effects on apparent digestibility of fat and energy and fecal characteristics. Int J Obes (Lond) 40, 1884-1890.

68. MacKinnon DP, Fairchild AJ \& Fritz MS (2007) Mediation analysis. Annu Rev Psychol 58, 593-614.

69. Reid IR (2004) Effects of calcium supplementation on circulating lipids: potential pharmacoeconomic implications. Drugs Aging 21, $7-17$.

70. Griffith LE, Guyatt GH, Cook RJ, et al. (1999) The influence of dietary and nondietary calcium supplementation on blood pressure: an updated metaanalysis of randomized controlled trials. Am J Hypertens 12, 84-92.

71. Allender PS, Cutler JA, Follmann D, et al. (1996) Dietary calcium and blood pressure: a meta-analysis of randomized clinical trials. Ann Intern Med 124, 825-831. 